\title{
THE IMPORTANCE OF THE USE OF IPV6 AS AN INTERNET MIGRATION PROTOCOL
}

\section{${ }^{1}$ Renan Cunha dos Santos Leitão, ${ }^{1}$ Anderson Eduardo de Ávila Silva, ${ }^{1}$ Bruno Pereira Gonçalves, 1'Jaqueline Silva de Souza Pinheiro, ${ }^{1}$ Josue Froner Freitas, ${ }^{1}$ Rilmar Pereira Gomes, ${ }^{1}$ Jean Mark Lobo de Oliveira and ${ }^{2}$ David Barbosa de Alencar}

\author{
${ }^{1}$ Academic department, University Center FAMETRO, Amazon-Brazil \\ 2Institute of Technology and Education Galileo of Amazon (ITEGAM), Brazil
}

\section{ARTICLE INFO}

\section{Article History:}

Received $17^{\text {th }}$ March, 2020

Received in revised form

$04^{\text {th }}$ April, 2020

Accepted $11^{\text {th }}$ May, 2020

Published online $29^{\text {th }}$ June, 2020

\section{Key words:}

Ipv4, Ipv6, Network, Internet, CGNAT.

*Corresponding author:

David Barbosa de Alencar

\begin{abstract}
The article states the need and importance of the migration from IPv4 to IPv6. All the information that this article contains was obtained from bibliographic research in several books and online papers, just as a survey with the people responsible for some companies' IT Department, in which we were able to attain a thorough analysis about the migration from IPv4 to IPv6. The currently situation of companies' systems have been unreasonably unstable with Carrier Grade Network Address Translation - CGNAT, a technique used by internet service providers to share IPv4 public addresses inside private network addresses. Some research indicates that a large amount of IT professionals are suitable to use the IPv6 migration system as well as states that there are several resources and technics for implementation of this new system, however there has to be caution while using dual stacks and tunnels from the more recent system, the IPv6, because some services still are operated by the older system, the IPv4, as long as it continues existing and being used. Nowadays, several internet providers have adopted a new way of using the IPv4 and the IPv6, but the industry lacks business owners or internet managers with the right conscious to obtain the equipment's that endure the migration to IPv6.
\end{abstract}

Copyright (C) 2020, Renan Cunha dos Santos Leitão et al. This is an open access article distributed under the Creative Commons Attribution License, which permits unrestricted use, distribution, and reproduction in any medium, provided the original work is properly cited.

Citation: Renan Cunha dos Santos Leitão, Anderson Eduardo de Avila Silva, Bruno Pereira Gonçalves et al. "The importance of the use of ipv6 as an internet migration protocol", International Journal of Development Research, 10, 06, 36816-36821.

\section{INTRODUCTION}

According to Kurose and Ross (Redes de computadores e a internet $\left.6^{\circ}-2016\right)$ the IPv4 Protocol Works as the model TCP/IP which operates a pattern of separated 32 bits: the first and second network are divided in five different classes: A, B, $\mathrm{C}, \mathrm{D}$ and $\mathrm{E}$. The IPv4 protocol has its own characteristics that determinate how it can be outdated by security flaws, minor data flow, decimal notation, numerous of address, etc. Pursuant to Brito and Henrique (IPv6 O novo protocolo da internet $1^{\circ}$ - 2013) the IPv6 Protocol operates by the same structure as the Ipv4 but uses addresses with 128 bits with hexadecimal notation separated by a network prefix and interface identifier. This protocol shows improvement on its characteristics of security, performance, management and mobility. The use of the IPv6 implicates in improvements where each of the devices have they're addresses to accomplish a quick response for an specific service, as well as some authority's audits.
Nowadays, the IPv4 protocol has sold out and survives by using the CGNAT which share the IP addresses. But that isn't a practical or recommended solution because can facilitate fraud. The IPv4 scenario is overloaded by many services that are just because innumerous amount of people is currently working from home, by the home office style. Another great factor that has to be noticed is that the CGNAT does not operate with a clean version of tracking accesses to a network, which does not help the authorities. One example of these circumstances is when a player is removed from a network because of a internet's server is overloaded. Therefore, this article has its aim in showing the importance of using IPv6 protocol and point how it works and what are the services it provides. The way of the migration from IPv4 protocol to IPv6 have been and it will continue to be discussed so the experts can find a way for the providers can work on the migration without disabling the older protocol. 
The importance of each protocol depends on the perspective: for the IT managers, it is the change in of how they deal with internet's services but for the costumers, it has a clear improvement on the use of their services. Knowing about the likely full capacity of the IPv4, there have been developed innumerable researches so there can be revealed Ips.

\section{BIBLIOGRAPHIC REVIEW}

Internet Protocols: Internet protocols are responsible of several worldwide connections. The IPv4 and the IPv6 have its own characteristics which pull one away from the other and making them incompatible. When the IPv4 was created, its creators have verified that it would be necessary to have over 4 billion internet addresses for the entire world but today this limit has probably been exceeded because of the progress of technology and the number of mobile devices. A solution for that was the creation of CGNAT system (Carrier Grade NAT) but today it is no longer efficient. Although the IPv4 and the IPv6 are different, they can operate some of the same equipment, then they can arrange a staged transition.

IPv4: The IPv4 was created by the ARPNET and was the principal protocol for making connection worldwide by shifting blocs of information between hosts. Its functionality uses a 32 bits scheme that allows formation of IPs with scales of 4 numbers, for example: one of class C: 192.168.1.1 which numbers have a minimum address of 0.0.0.0 to 255.255.255.255. This protocol works as OSI network model and TCP/IP internet model (see figure 01).

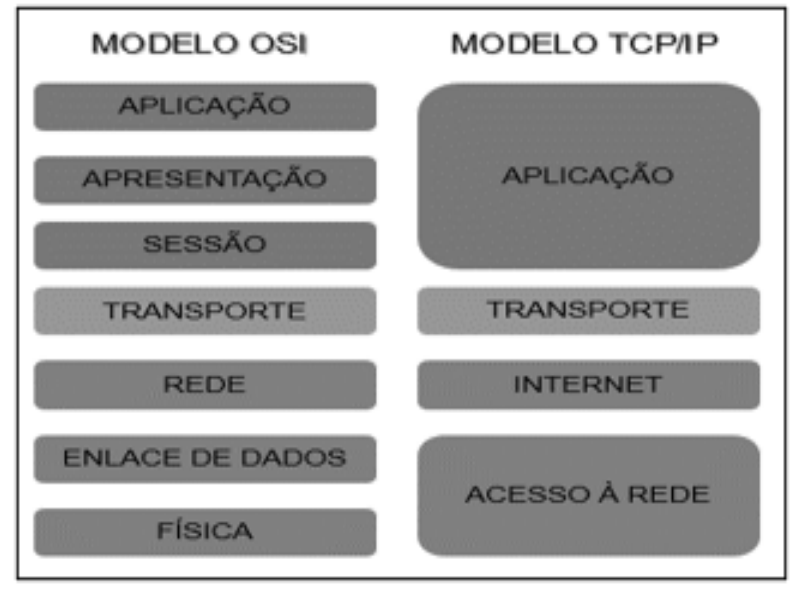

Source: Own Authorship. 2020.

Fig. 01. Models OSI and TCP/IP

This decimal scheme corresponds to a binary conversion which divides the numbers in four scales, creating the IPv4 protocol. Its addressing manners are determined by three different types: unicast, an only junction can be used for sending and receiving information; transmission, in which all the devices connected to a network can receive diagrams; and the multicast, that combine the two previous methods, which is used on smartphones and videogame. The IPv4 addressing corresponds to the number of the network device. From professional's internet's routers to wireless networking and $3 \mathrm{G}$ or $4 \mathrm{G}$ modems, each device needs an IP address for it can connect between one another. In each device there are its own address with DHCP that can be found and find another networks equipment. Inside MS Windows' environment there has the possibility of contacting Network and Sharing Database.

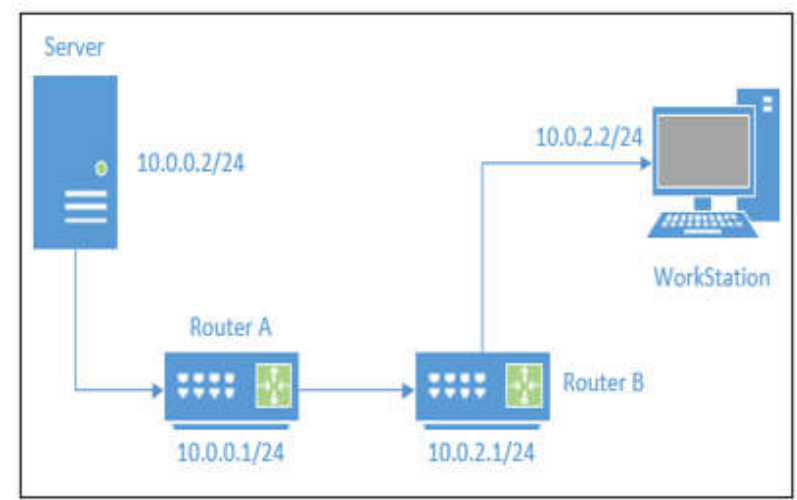

Source: Own Authorship. 2020.

Fig. 02. Internet's deliver system IPv4, MS Visio Project

DHCP: Every single routers are qualified for this type of service, the dynamic host protocol so called DHCP for services with TCP/IP, contains setups that can administrate local and global addresses throughout WAN and LAN doors with IP addresses according to its subnet. There are a lot of functionalities that are connected to the DHCP and bind it to an IP address for each MAC, where each one will have its IP address reserved.

IANA: The IANA (Internet Assigned Numbers Authority) is a worldwide organization that coordinate some of the key elements of the internet keeping track and supervising the overall allocation of internet, door, IP-addresses, systems' and domain name systems' - DNS, as well as providers. This organization announced in 2011 the delivery of last pack of IPv6 for the African and Asian continents as a reminder that the IPv4 addresses are outdated.

CGNAT: All technology has its main features and properties accordingly with different types of hardwires and softwires, just as the internet which can be used for good or evil. CGNAT was adopted since the announcement of the ending of the fabrication of the IPv4 system while used to share addresses of the ancient system to several clients and other people, such as demonstrated in the Figure 03 showed below. The CGNAT brought a breakdown in the connectivity end-toend for services such as voice calls, IP videos, online games, inter alia. This system has been used by companies that provides internet to clients, because with it some services can improve their performance.

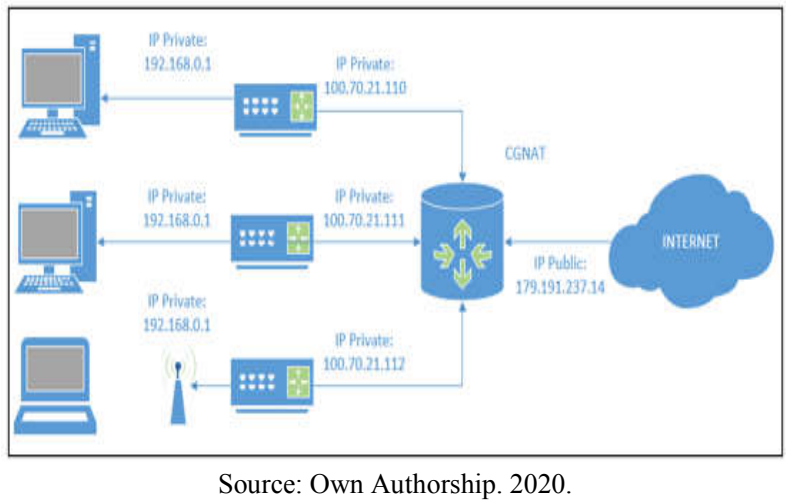

Fig. 03: Functioning of the CGNAT, MS Visio Project.

Google Forms: This platform is well known as a free tool designed by google in order to assist the data collection by questionnaires with questions that can provide graphics with the results. 
Zabbix: Zabbix is a tool with several functions with the purpose of monitoring networks infrastructure and other implementations. It was created in 1998 and was launched in 2001 , but still is one of the most accessed platforms the tracks internet providers for companies' network links and for their costumers (See Figure 04). In the figure above, there can be seen that the principal links of internet provider which monitoring is done by live data through Zabbix platform. At the moment that the link shows any defect, the graphic announces it.

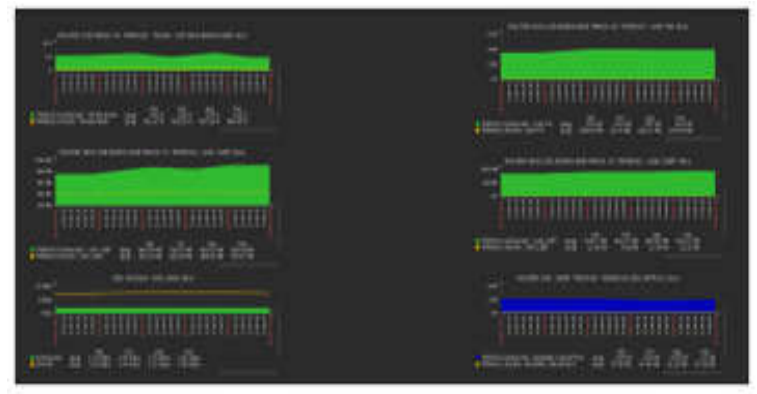

Source: Own Authorship. 2020.

Fig. 04: monitoring of Zabbix

MS Vision: The MS Vision is a tool created by Microsoft in the year 2000 so they were able to create diagrams inside Windows environment, but it is available to a in numerals operational systems. This program has been used for UML, process, flowcharts, database modelling, among another.

\section{MATERIALS AND METHODS}

The method chosen to elaborate this article was the bibliographic research in books and internet articles about IPv4 and IPv6 Protocols, CGNA as well as computers servers. The database was acquired by a quantitative survey trough a questionnaire with ten questions for companies' IT servers. And the analysis about the information obtained from the survey was adopted a descriptive study. The survey was made using Google Forms platform, a tool that assist the data storage through questions, and the monitoring of the internet server was supported by Zabbix platform, which assist the monitoring of data and the internet traffic. To create the network's diagrams, it was used a MS Visio tool that offer a better sight of the server.

\section{RESULTS AND DISCUSSION}

Current Scenario: At present days, the Ipv4 still is a strong protocol because it a system that many of the professionals know how to use from basic to advanced knowledge and for a long period of time it has been the most used protocol. The internet wasn't only a military experiment, it has grown greatly since its creation and the number of connected devices is still raising. Therefore, also has increased the shortage of number of IP's, reducing the effectiveness of the CGNAT as it cannot support the quantity of people and devices connected. CGNAT has its particularities such as: the malicious costumer (see Figure 05) and the well-intentioned costumers that share an IP public address (see Figure 06). In this scenario there is a malicious costume currently known as hacker that, for example, executes fraud in banks, but uses a public IP provided by his internet provider without using CGNAT which turns it available for tracking him when armed with judicial order, so the authorities can verify which costumer was using that determined IP.

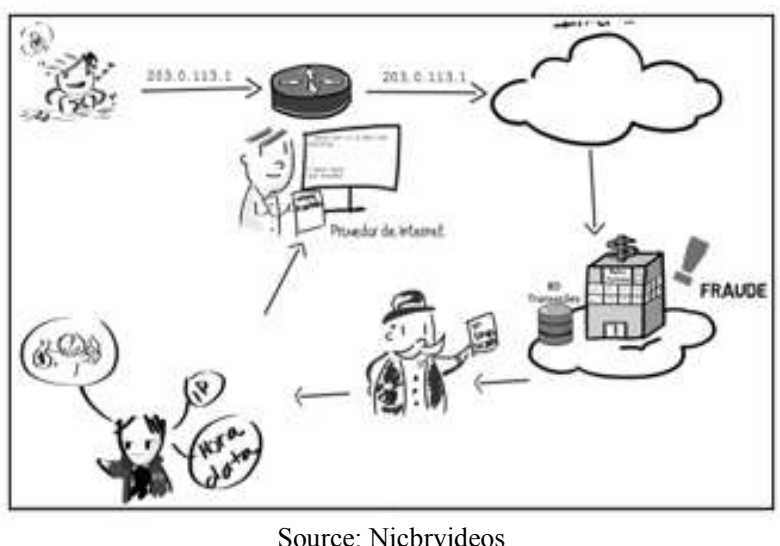

Fig. 05. Malicious costumer

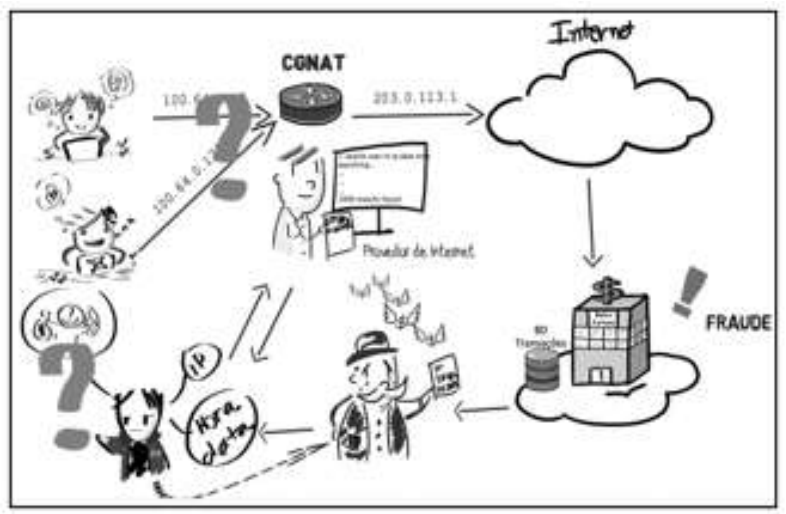

Source: Nicbrvideos

Fig. 06. Costumers using CGNAT

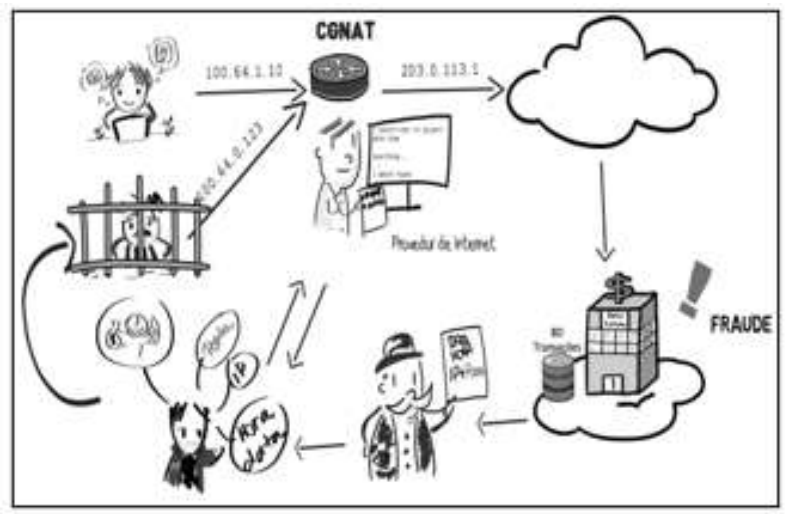

Source: Nicbrvideos

Fig. 07. CGNAT of gates

Differently from the scenario explained above, in this one there is the hacker and an usual costumer that were using the same public IP address with the assistance of CGNAT. The provider creates a range of private IP that is suited for its internal network, but with a public IP. In this case, there is no way for tracking de malicious costumer because the is no register of which private IP was used. One of the solutions available, and the most effective, was adopted by the Figure 07 below. In the Figure above there's the same scenario, but in this case it all gets registered because of the existence of a system of doors of all the users, so their steps keep stored on that system also on the internet provider. When an expert executes an investigation, they find logs of access information inside the system of doors. 


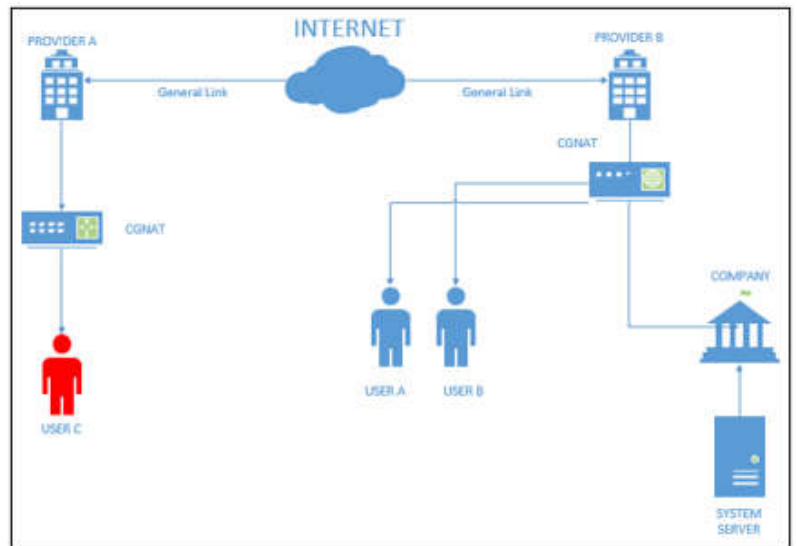

Source: Own Authorship. 2020.

Fig. 08: CGNAT home office example

This scenario is about a particularity in which the IPv6 protocol can be introduces, such as when everyone would have to work at home, as it is popularly known as home office (Figure 08). In this example, user named as A and B work in a company and use the same internet server. They could not sense the latency to access their company's internet because they share one IP address from the company's CGNAT. Otherwise, the user named $\mathrm{C}$ has its internet from another server will feel the latency because the internet does not have $\mathrm{n}$ public address. Therefore, he will not be able to access some of the applications the other two will.

The monitoring: The monitoring is very important for internet providers to verify the medium usage of their principal links so that they can deal with the exhaustion of the speed rate of internet when, for example, all of their clients are working home office (See figure 09). In 1 hour of monitoring the link on March 31, 2020 we were able to verify that it stood regularly above $90 \%$ of its capacity as it can be confronted with the Figure 10. The same monitoring was realized on October 31, 2019, when it established only in the use of $30 \%$ of its capacity because its customers were not working home office all the time.

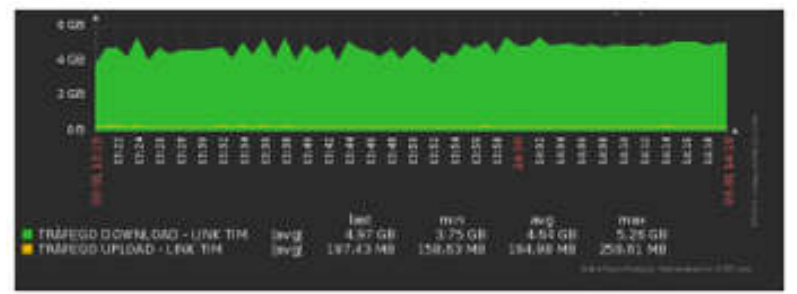

Source: Own Authorship. 2020.

Fig. 09. Principal Link monitoring

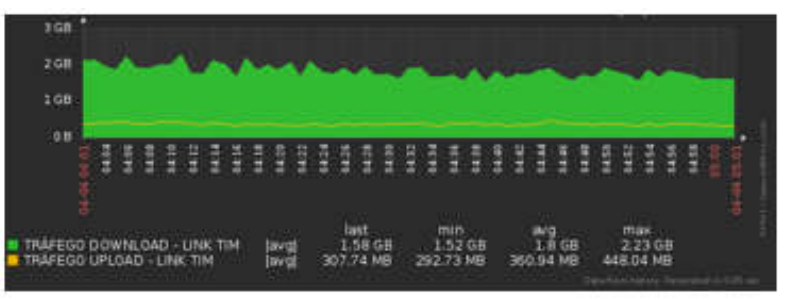

Source: Own Authorship. 2020.

Fig. 10: Principal Link monitoring

The transition: The transition means there is a coexistence between IPv4 and IPv5 Protocols that are simultaneously adopted so the implementations of the IPv6 can be installed. Some of the techniques are described by its features:

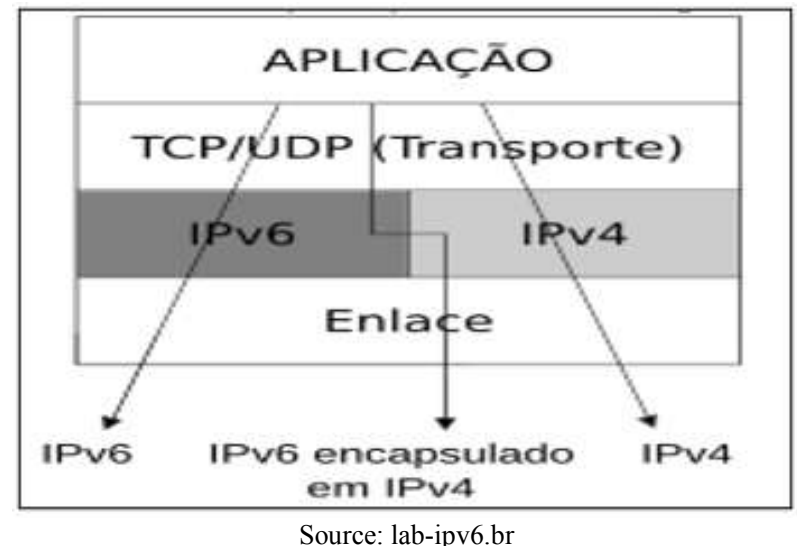

Fig. 11: Functioning of the de dual stack system

- Dual stacks: coexistence between IPv4 and IPv6 in the same equipment.

- Tunnels: different IPv4 servers can exchange data through an IPv6 system, vice versa.

There has to be done a great analysis for the implantation of the IPv6 Protocol because there are several types of transition and it is hard to verify which one is the more efficient one. Dual stacks: this technique is the ideal way to migrate from IPv4 to IPv6 protocol because several services offered still operate with IPv4, but to do that all the services have to be suitable for the definite migration, such as when the internet server operate with IPv4 protocol, but the internal network or its devices support the IPv6. The Figure 01 below shows an example of the simultaneously delivery of the protocols.

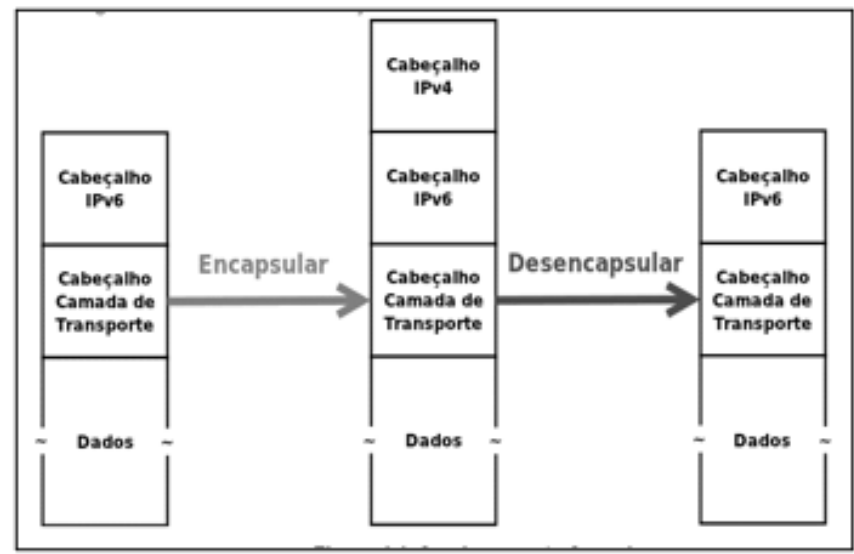

Source: lab-ipv6.br

Figure 12: Functioning of the tunnel system

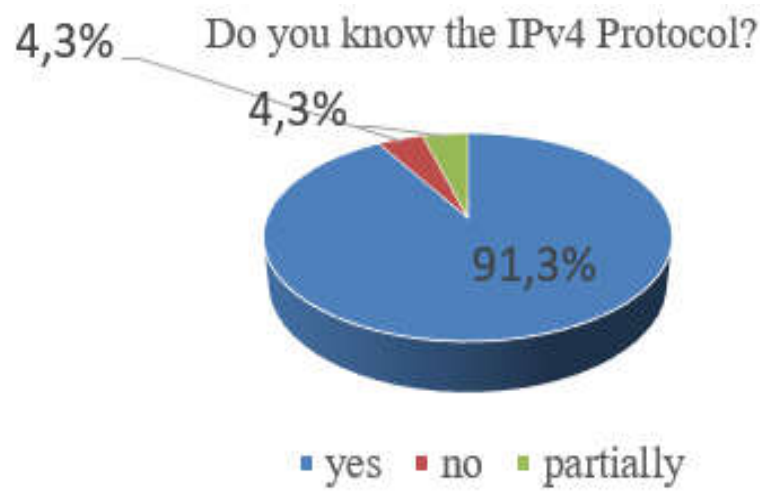

Source: The Authors, 2020.

Graphic 1: IPv4's Protocol 
It shows the delivery of an equipment that does not support IPv6 Protocol. In order to verify the correct functioning of the protocol there must be applied the command "ping6".

Surveys' results: The survey launched was executed for creating a database by IT costumer's opinions of the migration process from IPv4 for IPv6 for the IT public and ordinary people. From the questions made, it was possible to obtain the following results:

91,3\% of the respondents answered that they did know IPv4 Protocol. However, 4,3\% answered they did not know and the other $4,3 \%$ answered they know it partially. In most part it corresponds to IT professionals and users with at least a basic knowledge of network. This protocol persists the most known one that still is used because most of the softwires have not been developed to the IPv6.

\section{Do you know the IPv6 Protocol?}

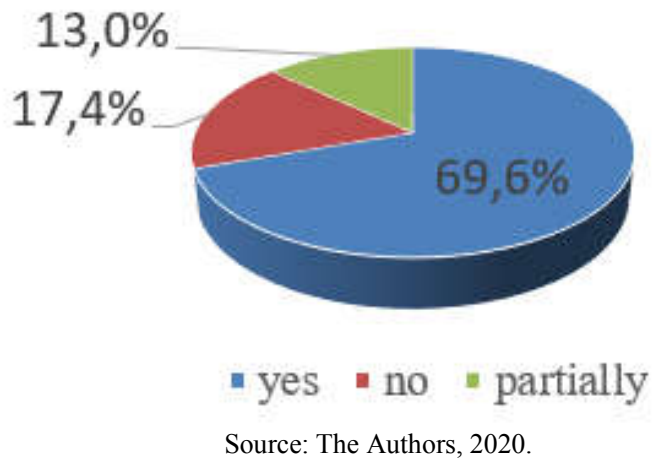

Graphic 2: IPv6's Protocol

$69,6 \%$ of the respondents answered that they did know IPv6 Protocol. However, 17,4\% answered they did not know and the other $13 \%$ answered they know it partially. In this case there is a high percentual because people have the knowledge of this protocol.

\section{Your company is suitable to receive the migration of Protocol IPv4 for IPv6?}

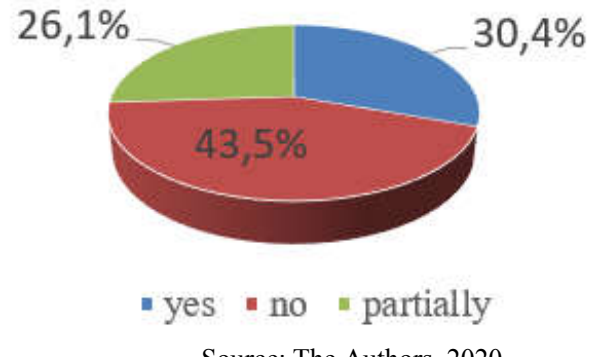

Graphic 3: Companies suitable to use the IPv6

$30,4 \%$ of the respondents answered that they did. However, $43,5 \%$ answered they did not and $26,1 \%$ answered they know it partially. Considering the need of equipment to attend the migration system from IPv4 to IPv6 because companies' managers do not invest on the technology department, or yet because their workers do note put the effort needed, a certain number of companies are not ready for this migration. It does not depend only in the internet server to deliver the IPv6 service since every company is responsible for its inner network and systems.

\section{Do you consider necessary the migration from IPv4 to IPv6?}

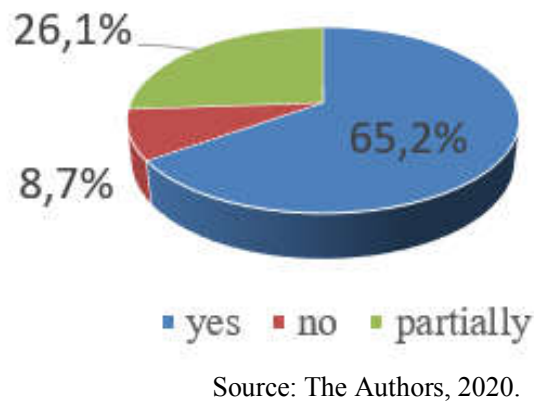

Graphic 4: Is there a need for the migration to IPv6?

$65,2 \%$ of the respondents answered that they thought it is necessary, 26,1\% answered they did not know for sure e $8,7 \%$ answered that they did not consider necessary.

The answer for this survey is that the public that knows the difference between IPv4 and IPV6 approves the most recent one (IPv6) because its inner purpose is to turn the development of the softwires much greater, as well as the traffic flow of information, the security of them and the ability to prevent fraud.

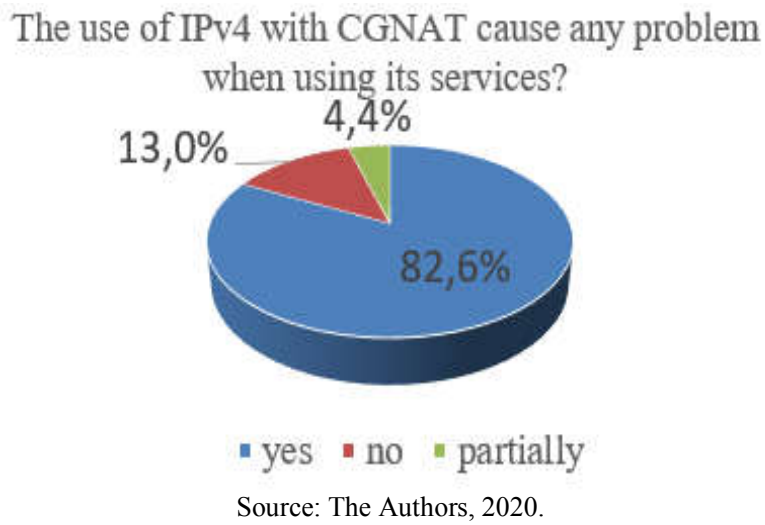

Graphic 5: IPv4's problems

$82,6 \%$ considered that even while using the IPv4 with CGNAT caused problems in its services, $13 \%$ considered it did not and $1 \%$ answered it partially caused problems. Most people that participated in the survey considered the IPv4 is a system that generate problems when sharing information, such as it occurs when people have to work from home sharing the same CGNAT. These are the most important questions to consider when approaching the migration.

\section{Conclusion}

From all the information acquired from the bibliographic research and from the results of the survey it is possible to verify that companies need the IPv6 migration because most of the IT server consider that the IPv4 is exhausted and the search for public internet server is higher. The costs for a company to order a public IP address so there can be used exclusive VLAN and VPLS for their customers will not disturb the security of the internet even in global server. It can be realized that every time that a costumer understands the benefits of a public IP, it contacts its seller searching it. Furthermore, considering the opinion of the internet server, network managers and businessmen, the system IPv4 must be migrated to IPv6. The 
IPv6 will reduce the percentage of virtual attacks because of its tracking ability from access' improvements between server and client, making the simultaneously access easier. This should be the perfect scenario where IPv4 would not be available and the IPv6 would gain the worldwide connection.

\section{Acknowledgments}

To God for our lives and as a gratitude for giving us the strength we needed to have never given up. To our parents, friends and Family that helped us overcome barriers through all the years. To the teachers, as appreciation for all the instructions and guidance that helped us achieve our most honorable results.

\section{REFERENCES}

Comer, Douglas. Redes de computadores e Internet: transmissão de dados, ligações Inter redes, web e aplicações. 4. ed. São Paulo, 2004.
Equipe IPV6 BR. Laboratório de IPv6: Aprendanapraticausandoemulador de redes. 1. ed. São Paulo, 2015.

Henrique, Samuel; BRITO, Bucke. IPv6: O novo protocolo de internet. 1. ed. São Paulo, 2013.

IPV4, speedcheck, 2018. Disponívelem: <https://www. speedcheck.org/pt/wiki/ipv4/>. Acessoem: 10 de março de 2020.

IPV6BR. NicBR. 2019 PaginaInicial. Disponívelem: $<$ http://ipv6.br/>. Acessoem: 20 de fevereiro de 2020.

Jordâo, Priscila. Últimosblocos de endereço da internet IPv4 sãoentreguespelo IANA. G1, 2011. Disponívelem:

$<$ http://g1.globo.com/tecnologia/noticia/2011/02/ultimosblocos-de-enderecos-da-internet-ipv4-sao-entregues-pelo iana.html>. Acessoem: 13 de março de 2020.

Kurose, James F; ROSS, Keith W. Redes de computadores e a Internet: umaabordagem top-down. 3. ed. São Paulo: Pearson Education do Brasil, 2006.

Tanenbaum, Andrew S. Redes de computadores. 5. ed. São Paulo: Campus, 2011. 